\title{
Práticas Educativas Interdisciplinares de Leitura e Escrita.
}

Alessandra Cândida da Silva1; Gabriel Marques Bernardo2; Paulo Alexandre de Castro3; Leonardo Santos Andrade ${ }^{4}$; Geraldo Sadoyama5; Adriana S.P.Sadoyama ${ }^{6}$

\section{Resumo}

As Histórias em Quadrinhos (HQ) são uma ótima ferramenta pedagógica. Além de despertar interesse nos estudantes, permite que a mensagem seja transmitida de forma leve e eficaz. As HQ abrangem 4 áreas: ilustração, explicação, motivação e instigação. Sendo assim, o projeto tem por finalidade despertar a consciência ambiental, a criatividade, oferecer novas possibilidades musicais, desenvolver a prática da leitura e escrita através das Histórias em Quadrinhos. O projeto está sendo desenvolvido na Escola Municipal Patotinha com os alunos do $4^{\circ}$ ano B do Ensino Fundamental e pretende-se através do mesmo verificar o nível de leitura e escrita dos alunos afim de buscar uma construção de conhecimento de forma interdisciplinar. Os alunos pibdianos trabalharam de forma interdisciplinar o meio ambiente, a musicalidade, a leitura, escrita através do personagem Chico Bento nas

1 Professor Supervisor do PIBID Interdisciplinar/Regional Catalão/UFG. E-mail: alessandracandida2009@gmail.com

2 Discente do PIBID Interdisciplinar/Regional Catalão/UFG. E-mail: gabrielmarquesbernardo@gmail.com

${ }^{3}$ Coordenador de Área do Subprojeto Interdisciplinar - (PIBID, UFG/RC), E-mail: padecastro@ufg.br

${ }^{4}$ Coordenador de Área do Subprojeto Interdisciplinar - (PIBID, UFG/RC), E-mail: 1s_andrade@yahoo.com.br

5 Coordenador de Área do Subprojeto Interdisciplinar - (PIBID, UFG/RC), E-mail: gsadoyama@yahoo.com.br

${ }^{6}$ Coordenadora de Área do Subprojeto Interdisciplinar - (PIBID, UFG/RC), E-mail: drisadoyama@gmail.com 
diferentes disciplinas. O personagem foi escolhido por refletir características socioculturais do povo brasileiro. Trabalhou-se Histórias em quadrinhos (HQ), discussões sobre desenhos que falavam sobre a importância do consumo inteligente e da preservação ambiental e atividades lúdicas que trazem reflexões sobre os temas abordados. Os alunos estão tendo contato com novos estilos musicais, além de contar com a prensença de um cantor e tocador de viola, estilo musical regional. Além disso, os alunos tiveram uma maior aproximação com a leitura e escrita, e a oportunidade de conhecerem um pouco mais sobre a variação linguística. Os métodos avaliativos foram atividades orais e escritas, observação em sala, e provas no início, meio e fim do projeto, onde pôde-se acompanhar o desempenho dos alunos durante o processo de aprendizagem, buscando o desenvolvimento e a evolução do estudante. Observou-se uma grande evolução por parte dos alunos, houve uma maior conscientização nos aspectos musicais, ambientais, culturais e intelectuais. É visível o aumento da qualidade da escrita e leitura dos estudantes, tendo em vista que durante o ínicio do projeto eles apresentavam dificuldades com a dicção e o nervosismo. Observa-se uma leitura mais nítida e uma escrita melhor elaborada. $\mathrm{O} 4^{\circ}$ ano $\mathrm{B}$ é uma turma que conta com alunos interessados que buscam absorver novos conhecimentos, apesar da pouca idade. Os resultados parciais, do presente projeto, já conta com bons resultados, ao observamos o comportamento e o diálogo dos alunos. Apoio: PIBID/CAPES

Palavras Chave: Interdisciplinaridade, leitura e lúdico. 